\title{
SEPARATE AND INTEGRAL EFFECT TESTS FOR VALIDATION OF COOLING AND OPERATIONAL PERFORMANCE OF THE APR+ PASSIVE AUXILIARY FEEDWATER SYSTEM
}

\author{
KYOUNG-HO KANG ${ }^{1 *}$, SEOK KIM ${ }^{1}$, BYOUNG-UHN BAE ${ }^{1}$, YUN-JE CHO ${ }^{1}$, YU-SUN PARK ${ }^{1}$, and BYONG-JO YUN ${ }^{2}$ \\ ${ }^{1}$ Korea Atomic Energy Research Institute \\ 1045 Daedeok-daero, Yuseong-gu, Daejeon, 305-353, Korea \\ ${ }^{2}$ Pusan National University \\ *Corresponding author. E-mail : khkang@kaeri.re.kr
}

Received June 23, 2012

The passive auxiliary feedwater system (PAFS) is one of the advanced safety features adopted in the APR+, which is intended to completely replace the conventional active auxiliary feedwater system. With an aim of validating the cooling and operational performance of PAFS, an experimental program is in progress at KAERI, which is composed of two kinds of tests; the separate effect test and the integral effect test. The separate effect test, PASCAL (PAF $\underline{S}$ Condensing Heat Removal Assessment Loop), is being performed to experimentally investigate the condensation heat transfer and natural convection phenomena in PAFS. A single, nearly-horizontal U-tube, whose dimensions are the same as the prototypic U-tube of the APR+ PAFS, is simulated in the PASCAL test. The PASCAL experimental result showed that the present design of PAFS satisfied the heat removal requirement for cooling down the reactor core during the anticipated accident transients. The integral effect test is in progress to confirm the operational performance of PAFS, coupled with the reactor coolant systems using the ATLAS facility. As the first integral effect test, an FLB (feedwater line break) accident was simulated for the APR+. From the integral effect test result, it could be concluded that the APR+ has the capability of coping with the hypothetical FLB accident by adopting PAFS and proper set-points of its operation.

KEYWORDS : APR+, PAFS, PASCAL, Integral Effect Test, ATLAS, Condensation Heat Transfer, Natural Convection

\section{INTRODUCTION}

The APR+ (Advanced Power Reactor Plus) is a GenIII+ reactor, the standard design of which is currently being developed in Korea [1]. This reactor adopts new design features which are expected to improve nuclear safety and economic competitiveness. Whereas most conventional nuclear power plants (NPPs) have adopted an active concept of safety-related systems, the APR+ adopts passive systems for effective use of ECC (emergency core cooling) water and feedwater delivery to the secondary side of a steam generator (SG). The application of the passive safety systems can be considered a desirable method of achieving simplification, and increasing the reliability of the performance of safety functions in the new nuclear power plant design [2]. PAFS (Passive Auxiliary Feedwater System) is one of the advanced passive safety systems adopted in the APR+, which is intended to completely replace the conventional active auxiliary feedwater system [3]. PAFS cools down the steam generator's secondary side, and eventually removes the decay heat from the reactor core by introducing a natural driving force mechanism; i.e., condensing steam in nearly-horizontal U-tubes submerged inside the passive condensation cooling tank (PCCT). In order to satisfy the single failure criterion, PAFS is composed of two independent trains, and a single train of PAFS is designed to be capable of removing all of the decay heat from the reactor core during the anticipated accident transients.

In general, the use of passive systems has the advantages of reducing the costs associated with the installation, maintenance, and operation, and increasing the reliability of intended functions by eliminating the multiple pumps and valves. Careful design and precise validation on their performance, however, should be assured, due to the inherent weak driving forces of passive systems compared to active systems.

With an aim of validating the cooling and operational performance of the PAFS, an experimental program is in progress at KAERI (Korea Atomic Energy Research 


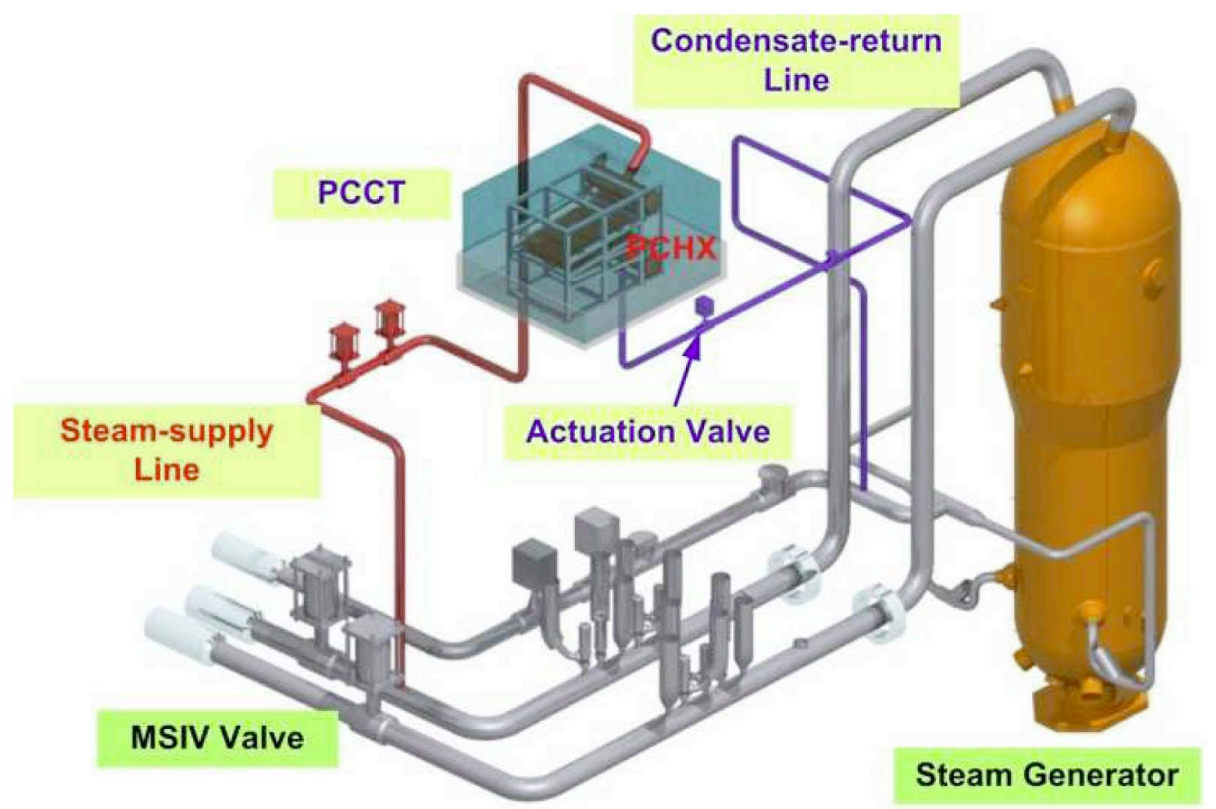

Fig. 1. Schematic Diagram of the APR+ PAFS

Institute), which is composed of two kinds of tests; the separate effect test and the integral effect test. The separate effect test, PASCAL (PAFS Condensing Heat Removal Assessment Loop), is in progress to experimentally investigate the condensation heat transfer and natural convection phenomena in PAFS. The integral effect test is being performed to confirm the operational performance of the PAFS coupled with the other reactor coolant systems (RCS) using the thermal-hydraulic integral effect test facility, ATLAS (Advanced Thermal-hydraulic test Loop for Accident Simulation) [4]. This paper summarizes the up-to-date experimental results of the separate effect test and the integral effect test for PAFS from a cooling and operational performance point of view.

\section{DESIGN FEATURES OF APR+ PAFS}

PAFS is composed of a steam-supply line, a passive condensation heat exchanger (PCHX), a return-line, and a passive condensate cooling tank (PCCT), as shown in Fig. 1. PAFS plays an essential role in removing the decay heat from the reactor core in a passive manner: i.e. condensation, boiling, and natural circulation flow. When the water level in the SG becomes lower than $25 \%$ of the wide range of the water level during an accident situation, the actuation valve at the return-water line is opened and the natural convection flow of PAFS occurs. It cools down the secondary system of the SG by heat transfer at the PCHX installed in the PCCT. The steam generated from the SG in the high pressure condition is condensed in the PCHX tube. The absolute pressure at the top of the PCCT is maintained at an atmospheric pressure, so that the natural convection flow accompanying boiling heat transfer at the outside wall of the PCHX tubes occurs in the PCCT pool side. Since the PCHX and the PCCT are located at a higher elevation than the $\mathrm{SG}$, condensate water can be returned back to the $\mathrm{SG}$ by gravity.

Fig. 2 shows a design of a PCHX bundle in PAFS. During the initial period of PAFS development, KAERI played a proactive role in designing the PCHX, whose preferential design requirements are to prevent an occurrence of a water-hammer phenomenon in the $\mathrm{PCHX}$, and to assure the cooling capacity during the anticipated accident transients. The inclination angle of the horizontal region is 30 , to prevent an occurrence of a water-hammer phenomenon in the PCHX. For the same reason, the dimensions of the PCHX were determined to limit a flow regime inside, by annular mist or horizontal stratified flow, and also to maintain a thermodynamic equilibrium quality of less than 0.0 at the outlet of the PCHX. In order to fulfill the heat removal requirement during the PAFS actuation, one bundle of the PCHX has 60 tubes in three rows, and the average length of the tubes is about $8.4 \mathrm{~m}$. The PCCT contains 4 bundles (240 tubes in total), where the bundles are placed in two rows on the bottom of the PCCT. The normal water level in the PCCT is $8.9 \mathrm{~m}$, so that it can remove the decay heat from the reactor core during 8 hours of hot shutdown by the evaporative heat transfer, as shown in Fig. 3. 


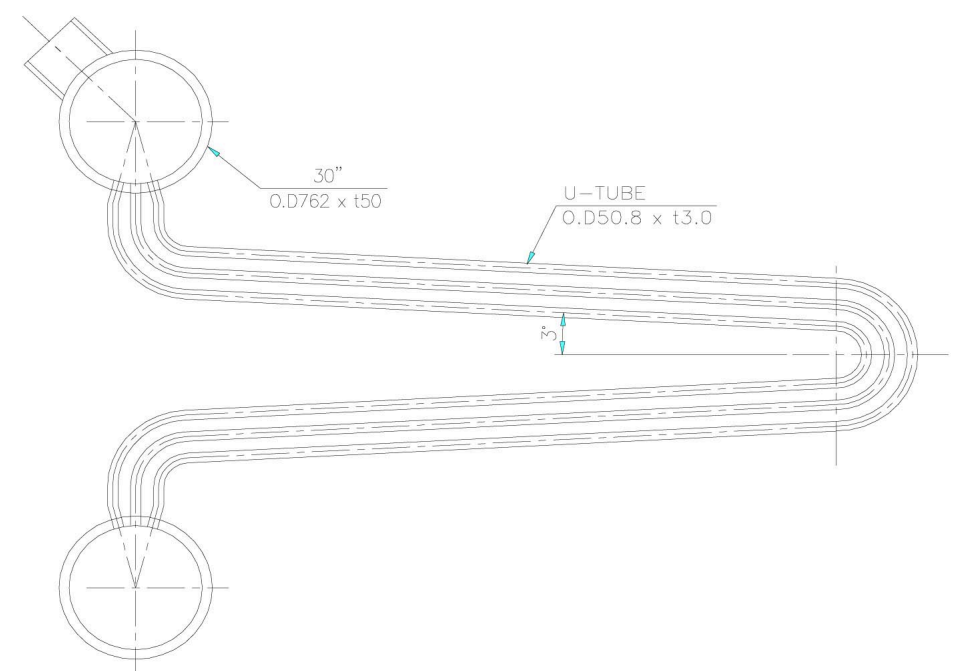

Fig. 2. PCHX Bundle of the APR+ PAFS

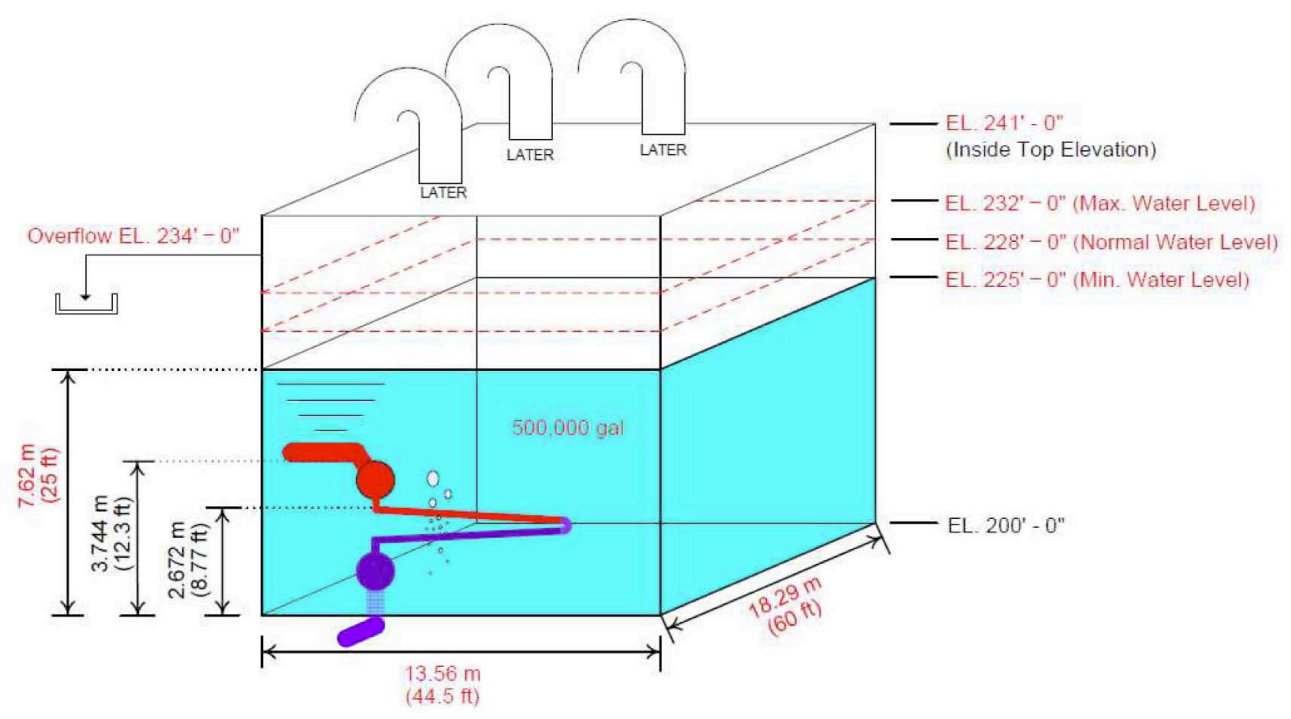

Fig. 3. Schematic Diagram of the PCCT

\section{SEPARATE EFFECT TEST PROGRAM}

\subsection{Overview of the Separate Effect Test}

Fulfillment of the heat removal requirement via PAFS was experimentally validated in the separate effect test, PASCAL. By performing the PASCAL test, the major thermal-hydraulic parameters, such as local/overall heat transfer coefficients, fluid temperature inside the tube, wall temperature of the tube, and pool temperature distribution in the PCCT, were produced not only to evaluate the current condensation heat transfer model, but also to present a database for the safety analysis related with PAFS. The PASCAL test is composed of 5 kinds of test items: Quasisteady state heat transfer test (SS), PCCT level variation test (PL), inadvertent MSSV opening test (TR), PAFS actuation test (SU), and non-condensable gas effect test (NC). The SS and PL tests were completed, and the cooling and operational performance of PAFS is discussed based on the experimental findings of the SS and PL tests in this paper. The effect of non-condensable gas and the start-up transient of PAFS will be investigated in the frame of the PASCAL test from the middle of 2012.

The PASCAL facility was designed according to a volumetric scaling methodology [5]. The methodology can conserve the elevation change between a heat source and a heat sink in a natural convection loop under the same pressure and temperature conditions. The PASCAL facility simulates a single tube among 240 tubes in the prototype, that is, the volumetric scaling ratio of the facility is $1 / 240$. The volume of the PCCT pool was also 
reduced to $1 / 240$ of the prototype. In order to preserve natural convection flow in the PCCT, the height of the water pool was determined to be the same as that of the prototype. The length of the PCCT was designed to be $6.7 \mathrm{~m}$, which is a half of that of the prototype, since the bundles are placed in two rows. Therefore, the width of the PCCT is $0.112 \mathrm{~m}$, which is equivalent to $1 / 120$ of that of the prototype. Major design parameters and scaling

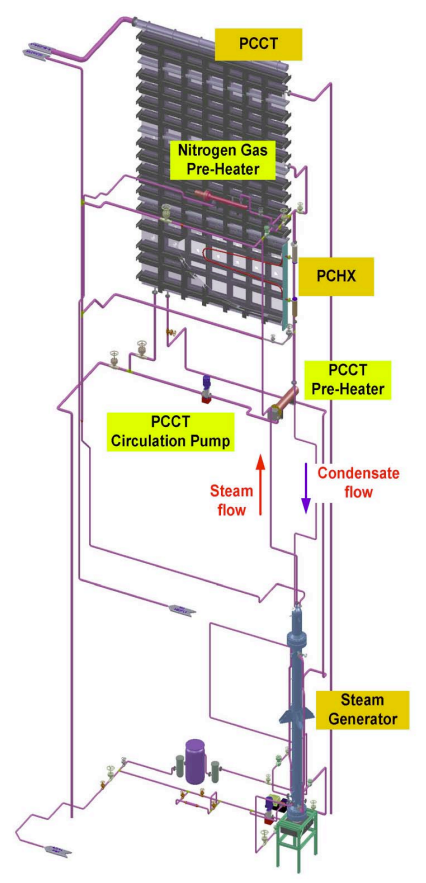

parameters are compared with the prototype in Table 1.

Fig. 4 shows a schematic diagram of the PASCAL facility. A steam generator in the PASCAL facility plays a role in supplying saturated steam to the PCHX tube. An electrical heater in the steam generator provides a heat source which scaled down the heat transfer rate at the Utube surface in the prototype steam generator. To conserve a driving force of the natural convection in the loop, a

Fig. 4. Schematic Diagram and Photograph of the PASCAL

Table 1. Scaling Parameter of the PASCAL Facility

\begin{tabular}{|c|c|c|c|c|}
\hline \multicolumn{2}{|r|}{ Parameter } & APR+ PAFS & PASCAL & Ratio \\
\hline \multirow{3}{*}{ PCHX } & Inner / Outer diameter & $44.8 \mathrm{~mm} / 50.8 \mathrm{~mm}$ & $44.8 \mathrm{~mm} / 50.8 \mathrm{~mm}$ & $1 / 1$ \\
\hline & Length & $8.4 \mathrm{~m}$ & $8.4 \mathrm{~m}$ & $1 / 1$ \\
\hline & Number of tubes & 240 & 1 & $1 / 240$ \\
\hline \multirow{4}{*}{ PCCT } & Pool height & $8.9 \mathrm{~m}$ & $8.9 \mathrm{~m}$ & $1 / 1$ \\
\hline & Pool length & $13.4 \mathrm{~m}$ & $6.7 \mathrm{~m}$ & $1 / 2$ \\
\hline & Pool width & $6.7 \mathrm{~m}$ & $0.112 \mathrm{~m}$ & $1 / 120$ \\
\hline & Elevation from SG level to PCCT bottom & $16.2 \mathrm{~m}$ & $16.2 \mathrm{~m}$ & $1 / 1$ \\
\hline \multirow{5}{*}{ Operating Condition } & Steam pressure & $7.86 \mathrm{MPa}$ & $7.86 \mathrm{MPa}$ & $1 / 1$ \\
\hline & PCCT pressure & $0.1 \mathrm{MPa}$ & $0.1 \mathrm{MPa}$ & $1 / 1$ \\
\hline & Steam flow rate & $95.04 \mathrm{~kg} / \mathrm{s}$ & $0.396 \mathrm{~kg} / \mathrm{s}$ & $1 / 240$ \\
\hline & Steam velocity in tube & $6.03 \mathrm{~m} / \mathrm{s}$ & $6.03 \mathrm{~m} / \mathrm{s}$ & $1 / 1$ \\
\hline & Thermal power & 129.8 MW & $540 \mathrm{~kW}$ & $1 / 240$ \\
\hline
\end{tabular}


distance between the mixture level in the steam generator and the PCHX tube was maintained to be equivalent to that of the prototype. The steam generator is connected to the PCHX tube with a steam-supply line and a condensatereturn line.

In the PASCAL test, major measuring parameters are the flow rate of the steam and condensate liquid, the loop temperature and pressure, the wall temperature of the PCHX, and the differential pressure on the steam-supply line and return-water line. Also, the collapsed water level and liquid temperature were measured in the PCCT pool. In order to study the local distribution of the heat flux and heat transfer coefficients of the PCHX, the surface temperatures at the inside and outside wall were measured at eleven points along the tube as shown in Fig. 5. At each point, the fluid temperature profile in a vertical direction was measured, so that the distribution of condensate liquid flow inside tube could be inferred.

\subsection{Experimental Conditions and Procedure of the Separate Effect Test}

During an actuation of PAFS, the pool water in the PCCT plays a role as the ultimate heat sink of decay heat. Evaporation by the heat transfer from the PCHX makes a decrease of the water level in the PCCT. In this study, with the given thermal power in the steam generator, a heat removal rate in the PCHX was measured, and the characteristics of the natural convection in the loop were investigated. Also the effect of the PCCT water level on the cooling performance of PAFS was experimentally investigated.

Five test cases of quasi-steady state heat transfer and PCCT water level decreasing were completed by varying the thermal power of electrical heaters in the steam generator from $300 \mathrm{~kW}$ to $750 \mathrm{~kW}$. In each test case, a quasisteady state condition of the system was simulated by the SS test, and the PL test was subsequently performed with an aim of investigating the thermal-hydraulic behavior

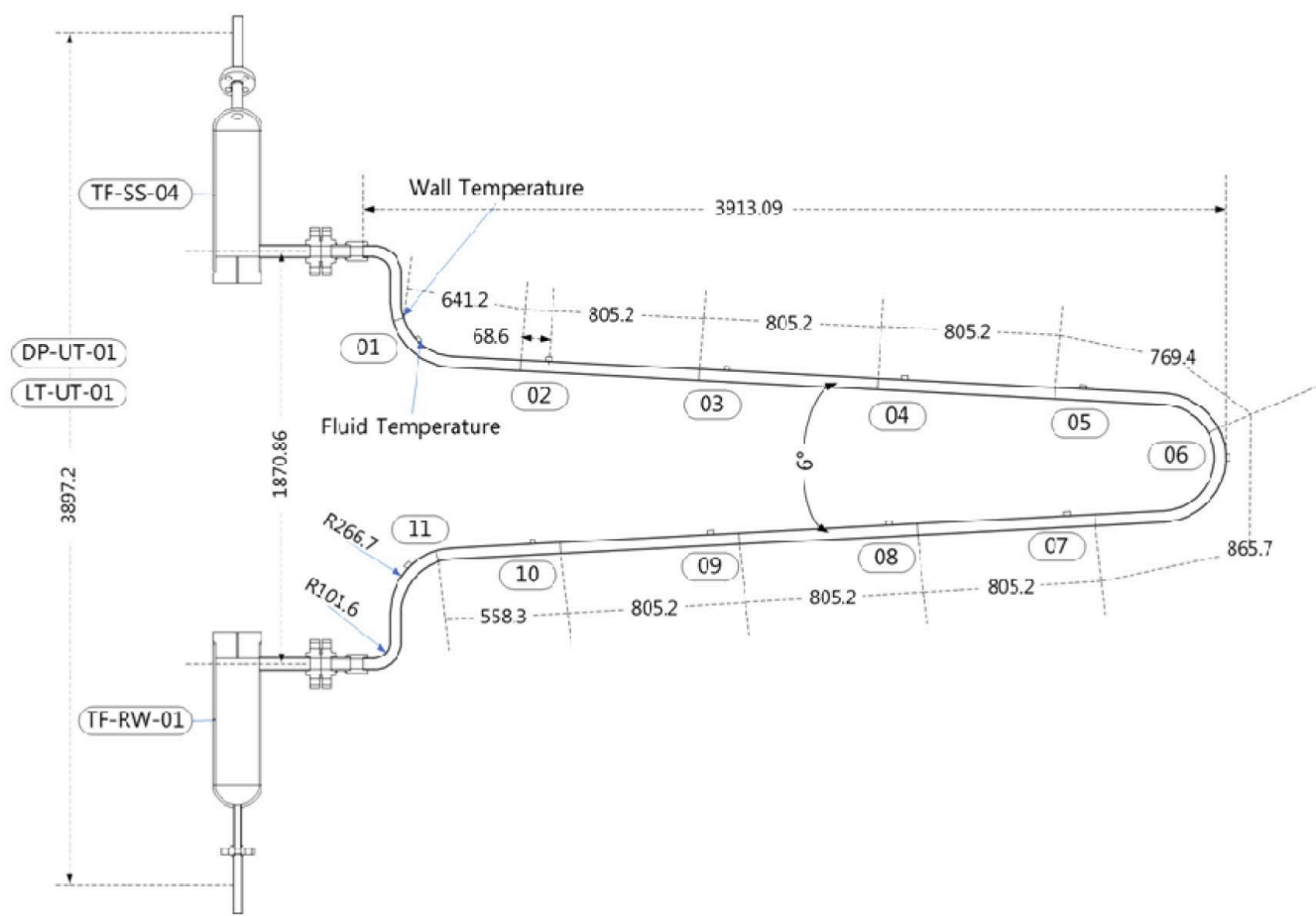

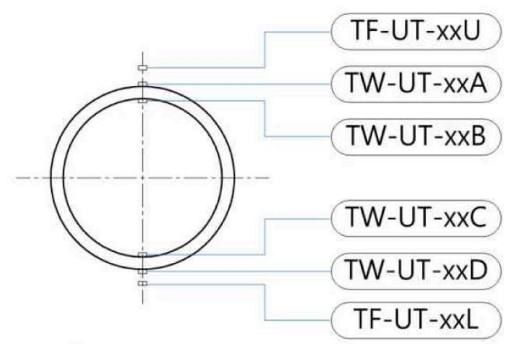

Wall Temperature

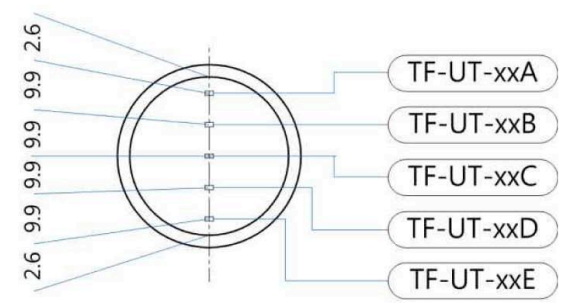

Fluid Temperature

Fig. 5. Measuring Location along the PCHX Tube in the PASCAL Facility (Dimension in mm) 
Table 2. Definition of Heat Removal Rates

\begin{tabular}{c|l}
\hline Notation & \multicolumn{1}{c}{ Description } \\
\hline HR-SG & Thermal power supplied by electrical heaters in SG \\
\hline HR-Tube & Heat removal rate of condensation heat exchanger calculated from summation of wall heat transfer rate \\
\hline HR-SS & Heat removal rate calculated from the flow rate in steam-supply line \\
\hline HR-RW & Heat removal rate calculated from the flow rate in return-water lin \\
\hline
\end{tabular}

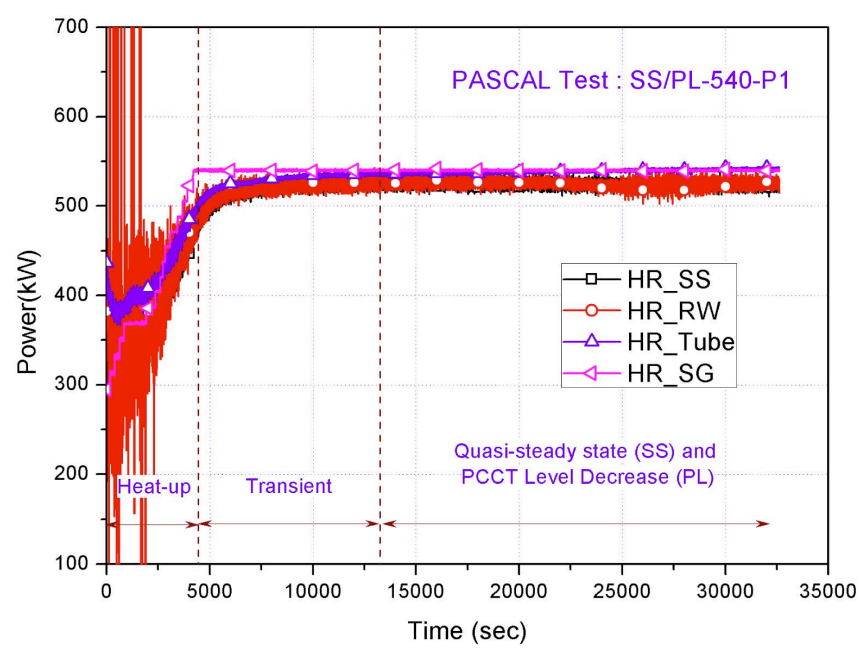

Fig. 6. Heat Removal Rates in the SS/PL-540-P1 Test

during the decrease of the water level in the PCCT. Since it is required for a single train of PAFS to remove 129.8 MW as a maximum heat removal rate during the accident transients of the APR+, the reference test condition was determined according to the scaling ratio of the facility as listed in Table 1. As for the required heat removal rate, the PCHX of PASCAL should have a capability of removing thermal energy of $540 \mathrm{~kW}$ as a scale-downed reference. Therefore, in the reference test, named as SS/PL-540-P1, $540 \mathrm{~kW}$ of thermal power was supplied in the steam generator heater as a rated power. The water in the PCCT was maintained in the saturated state at an atmospheric pressure. When the pressure, temperature, and flow rate reached a steady state at the constant thermal power condition, the heat removal rate and the natural convection flow were measured.

\subsection{Experimental Results of the Separate Effect Test}

In the PASCAL test, the heat removal rates in the PCHX can be classified as listed in Table 2, which includes the summation of the surface heat transfer rate of the PCHX (HR_Tube), and the enthalpy decrease between the inlet and the outlet of the PCHX (HR_SS and HR_RW, respectively). Among the various definitions of the heat removal rates, the rate in the PCHX tube (HR_Tube) is the most reliable value in the PASCAL test. Fig. 6 compares the heat removal rates of the continuous thermal power in the SS/PL-540-P1 test. As shown in Fig. 6, the amount of heat transfer in the PCHX increased until the data acquisition time of 13200 seconds, according to the increase of the supplied thermal power in the SG. During the quasisteady state condition (from time of 13200 to $13300 \mathrm{sec}$ onds), the heat removal rate in the PCHX tube (HR_Tube) was equivalent to the supplied power (HR_SG). After the quasi-steady state, the heat removal rates increased, due to an increase of boiling heat transfer in the PCCT pool side, which was attributed to the lower saturation temperature induced by the lower static head. The pressure, the temperature, and the natural convection flow rate of the steam generator system decreased as presented in Fig. 7 .

Fig. 8 shows a variation of the PCCT water level in the SS/PL-540-P1 test. By a boiling heat transfer from the PCHX tube, the collapsed water level of the PCCT continuously decreased. The lower water level in the PCCT induces lower pressure and a lower saturation temperature of the pool water around the PCHX tube, so that a decrease of the PCCT water level results in a larger amount of the nucleate boiling on the tube surface. It made a boiling heat transfer coefficient at the outer wall of the tube increase, as shown in Fig. 9, while the condensation heat transfer 

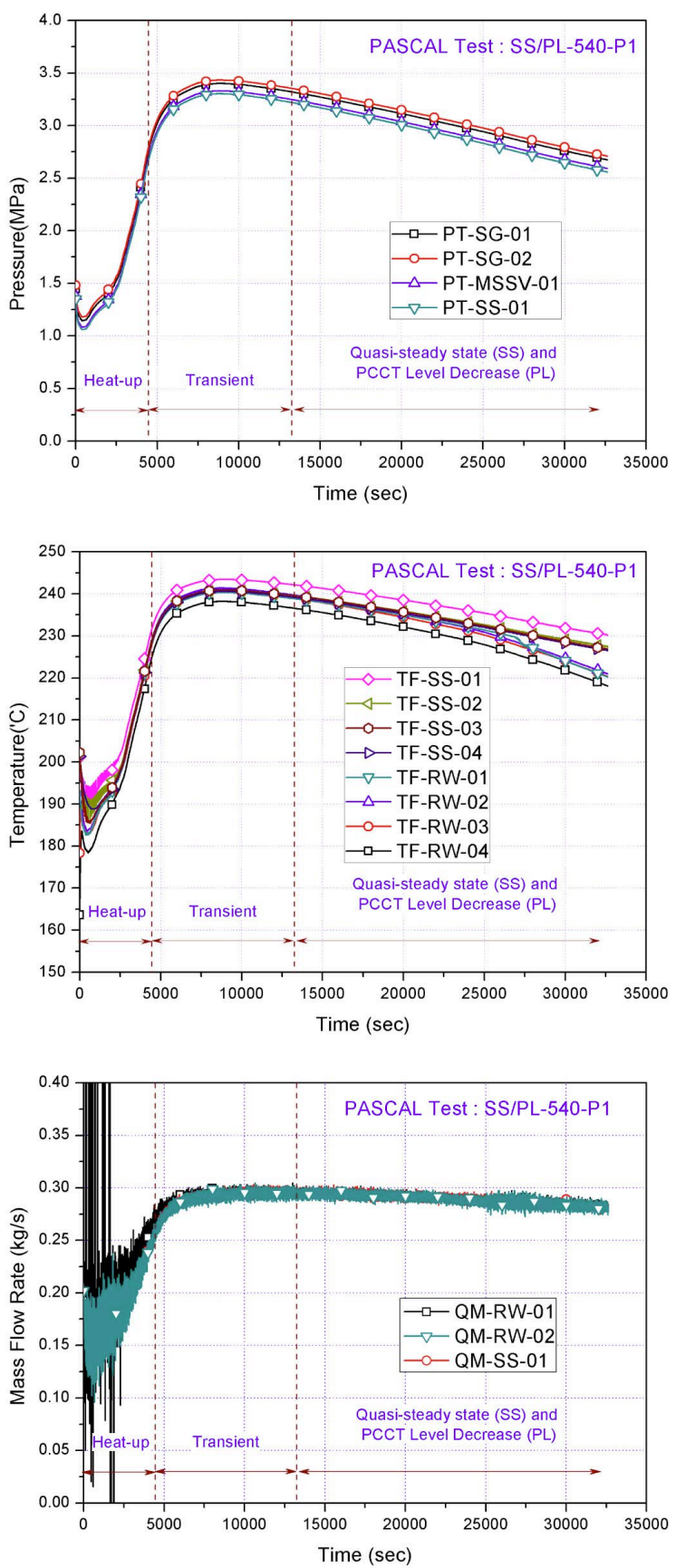

Fig. 7. Variation of Thermal-hydraulic Parameters in the SS/PL-540-P1 Test

coefficient at the inner wall presented a relatively uniform profile, as shown in Fig. 10. Therefore, the increased heat removal from the PCHX, according to the decrease of the PCCT water level, resulted in a decrease of the system pressure and temperature as shown in Fig. 7.

When the PCCT water level was high, the bubbles were condensed after departing from nucleation sites on the tube surface and a significant void was not observed

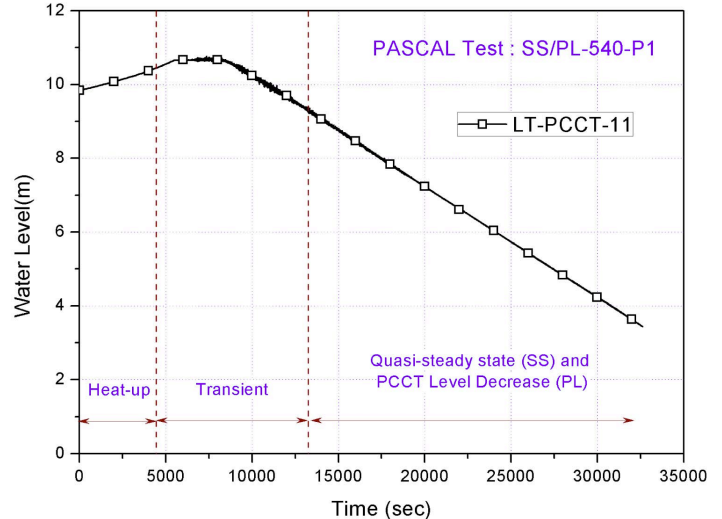

Fig. 8. Variation of PCCT Water Level in the SS/PL-540-P1 Test

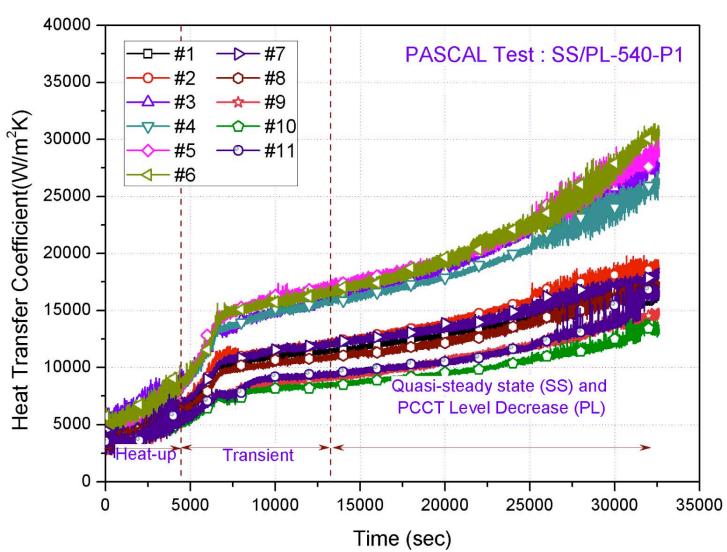

Fig. 9. Boiling Heat Transfer Coefficients in the SS/PL-540P1 Test

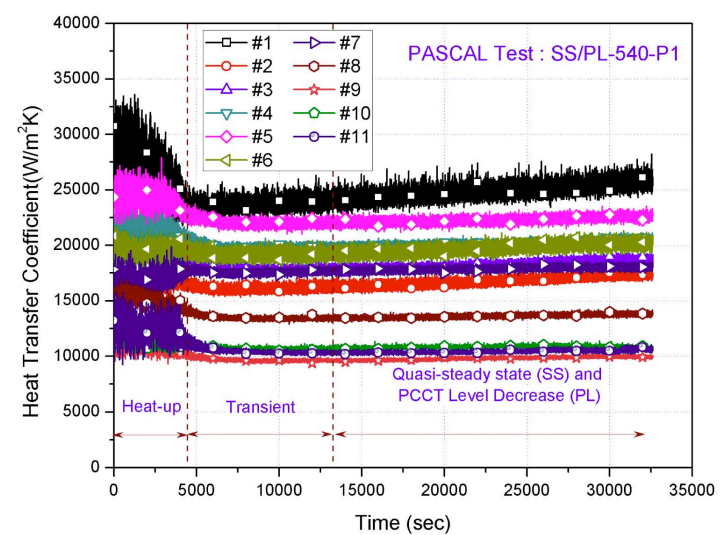

Fig. 10. Condensation Heat Transfer Coefficients in the SS/PL-540-P1 Test

through the windows on the PCCT side wall. As the water level in the PCCT was reduced by evaporation, the degree of subcooling of pool water around the tube became smaller, due to the decrease of static pressure. As the water level in the PCCT became lower, more bubbles, with a larger 

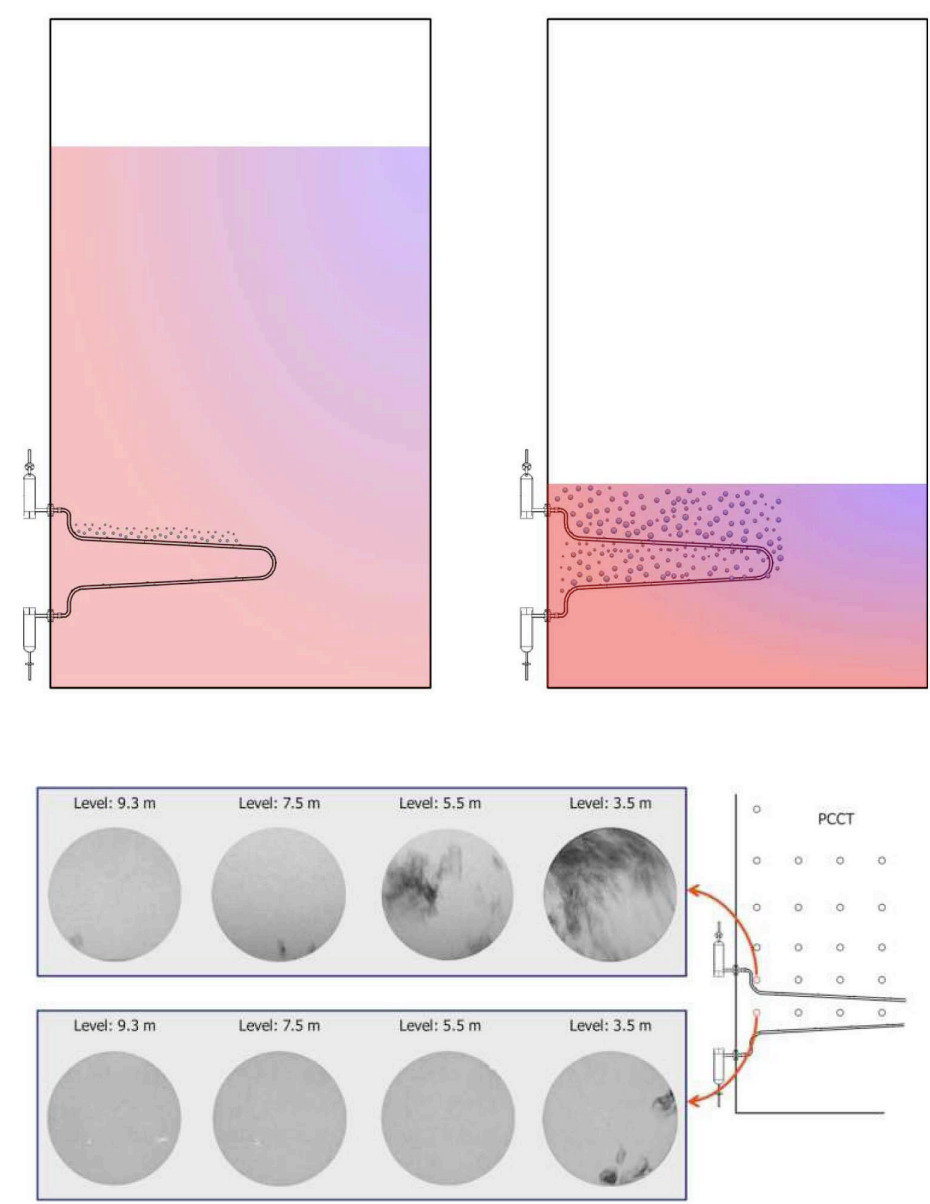

Fig. 11. Visualization of Bubble Behavior of the PCCT Pool in the SS/PL-540-P1 Test

size, could be observed through the windows around the PCHX tube, as shown in Fig. 11.

As the steam flowed toward the outlet, the heat flux decreased, due to the lower wall temperature, which was induced by the subcooled liquid flow. Since the top part of the tube was filled with the steam flow and the condensate liquid flowed in the bottom region inside the tube, the condensation heat transfer coefficient at the top region of the inner wall was larger than that of the bottom region, as shown in Fig. 12. The phase distribution inside the PCHX can be confirmed from the fluid temperature contour plotted in Fig. 13. According to the distribution of the fluid temperature inside the PCHX, it was found that a stratified flow appeared along the whole length of the tube. This is in good agreement with the criterion for preventing a condensation-induced water hammer phenomenon inside the tube.

The temperature distribution in the PCCT pool was depicted in Fig. 14. The temperature above the PCHX tube showed the highest value induced by the larger heat flux in the upper part of the tube. The heat transfer from

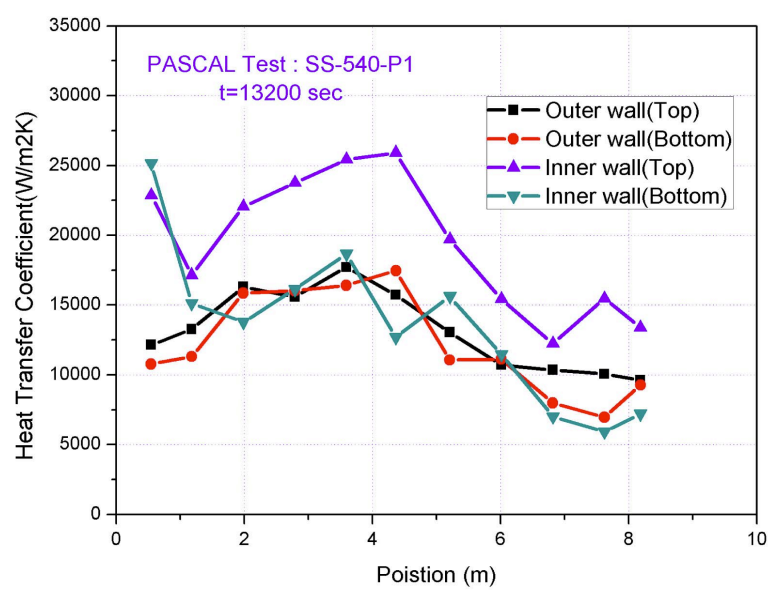

Fig. 12. Heat Transfer Coefficients at Steady-state Condition in the SS/PL-540-P1 Test

the PCHX contributed to increase the pool temperature up to the saturated condition, and induced the natural 


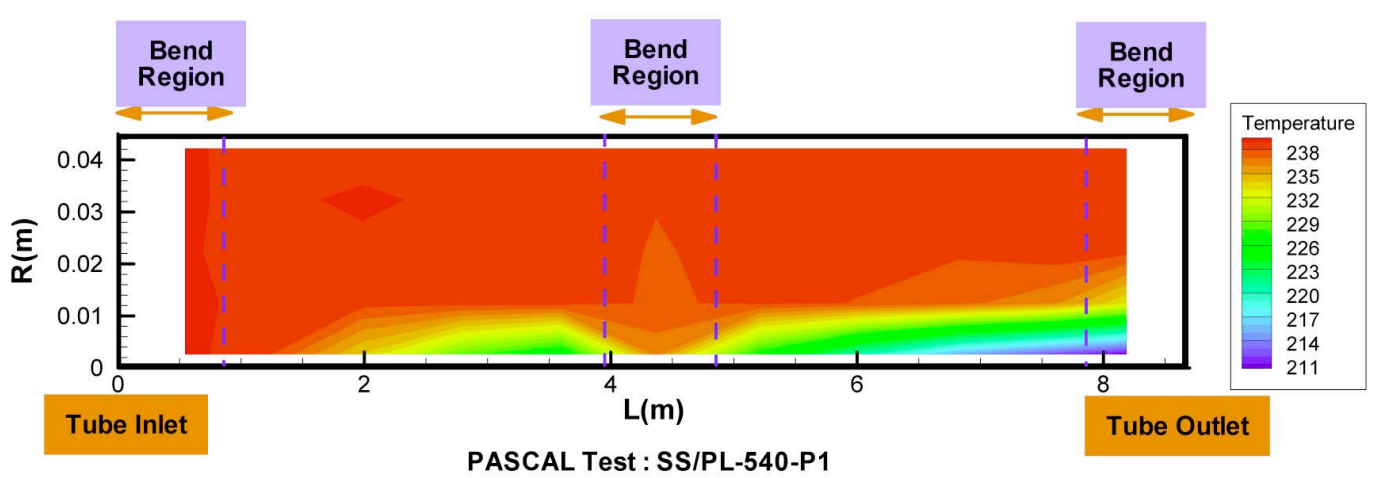

Fig. 13. Fluid Temperature Contour Inside the PCHX in the SS/PL-540-P1 Test

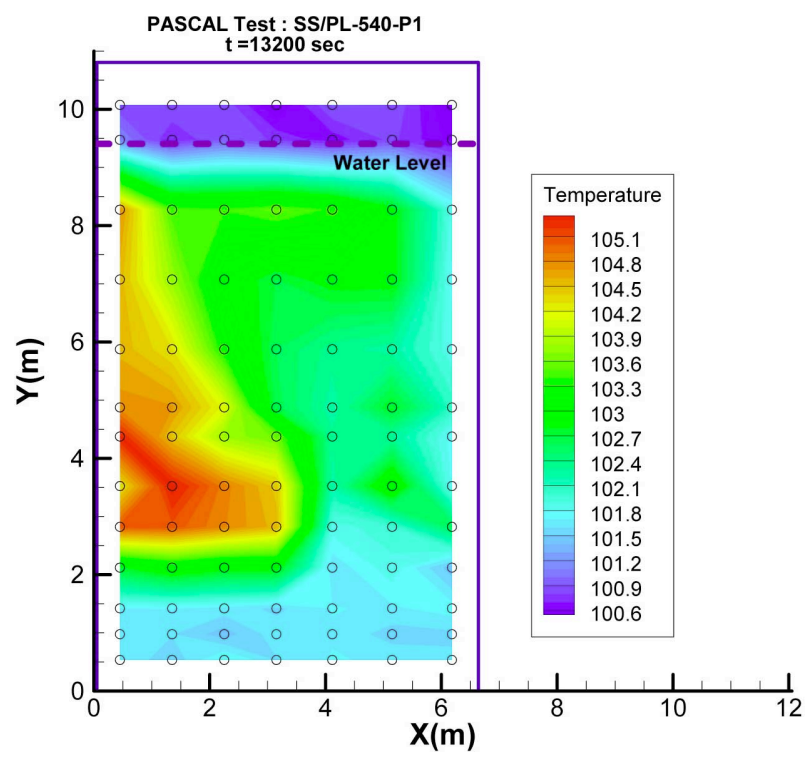

Fig. 14. Fluid Temperature Contour Inside the PCCT in the SS/PL-540-P1 Test

circulation flow of the PCCT pool water. For a 2-D incompressible flow, vorticity and temperature distribution were analogous of each other. Since the vorticity is perpendicular to the velocity gradient, the streamlines are theoretically perpendicular to the isothermal lines. During the initial transient periods, convective flows started to appear in the PCHX inlet region. At a quasi-steady state, temperature distribution showed a large circulation flow above the PCHX, as shown in Fig. 14.

Fig. 15 shows the steam pressure at the quasi-steady state condition, according to a variation of the thermal power in the SG. Since the maximum pressure was near 6.7 $\mathrm{MPa}$ in the case of the $750 \mathrm{~kW}$ applied test, it was concluded that the PASCAL facility could cover a whole operating region of PAFS. Also, it was experimentally proved that the present design of PAFS has an adequate thermal margin.

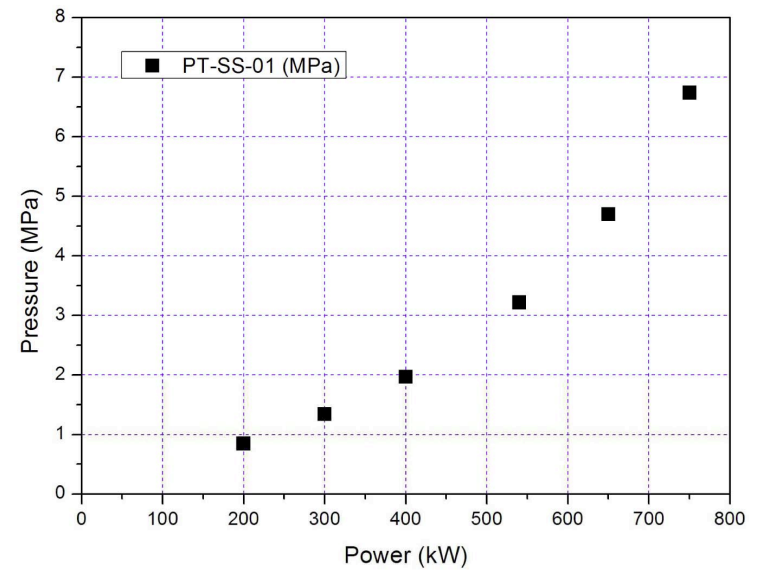

Fig. 15. Steam Pressure According to the Applied Thermal Power at Steady State Condition

\section{INTEGRAL EFFECT TEST PROGRAM}

\subsection{Overview of the Integral Effect Test}

The main objective of the ATLAS-PAFS integral effect test is to investigate the thermal hydraulic behavior in the primary and secondary systems of the APR+ during a transient when PAFS is actuated. Since the ATLAS-PAFS facility simulates a single train of PAFS, the anticipated accident scenarios in the experiment include FLB (Feedwater Line Break), MSLB (Main Steam Line Break), and SGTR (Steam Generator Tube Rupture). Among them, an FLB was considered as the most important accident in evaluating the cooling capability of PAFS, during the development of PIRT (Phenomena Identification and Ranking Table) [6]. Therefore, the test for simulating an FLB was determined to be the first integral effect test item in the frame of the ATLAS-PAFS experimental program.

ATLAS is a thermal-hydraulic integral effect test facility whose reference plant is the APR1400 (Advanced Power Reactor $1400 \mathrm{MWe}$ ). ATLAS is designed according to the well-known scaling method suggested by Ishii and 
Kataoka [7] to simulate various test scenarios as realistically as possible. Since the APR+ has a similar geometry and loop configuration compared to the APR1400, the ATLAS facility can be appropriately utilized to simulate the FLB transient in the APR+. ATLAS is a half-height and 1/330volume scaled test facility with respect to the APR+. A realistic, 3-dimensional view of ATLAS is shown in Fig. 16.

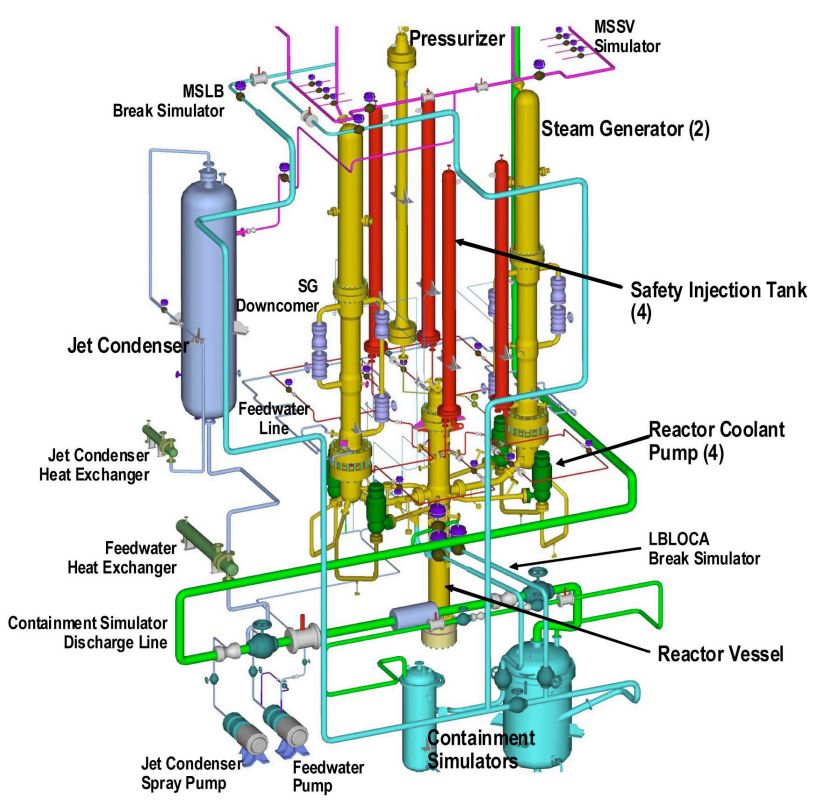

Fig. 16. 3-Dimensional View of the ATLAS
In order to allow for a simulation of high-pressure scenarios, the loop is designed to operate up to $18.7 \mathrm{MPa}$. A detailed ATLAS design and description of the ATLAS development program can be found in the literature [8].

As the first integral effect test for PAFS, the PAFSFLB-EC-01 test was performed to simulate an FLB on the pipe connected to the steam generator \#1 (SG-1) economizer with an equivalent break size of $0.3 \mathrm{ft}^{2}$, which was analyzed as the most severe case in the APR+ SSAR (Standard Safety Analysis Report) [9]. Since the break nozzle is placed on the feedwater line of the SG-1, PAFS was connected to the SG-2 of ATLAS. PAFS was composed of the PCHX, the PCCT, the steam-supply line, and the return-water line as shown in Fig. 17.

Fig. 18 shows a schematic diagram and a photograph of the PCHX in the ATLAS-PAFS. Contrary to the use of a single tube in the PASCAL test, the PCHX in the ATLAS-PAFS has three tubes whose dimension was determined to conserve the heat transfer rate at the surface according to the scaling methodology. A reduced diameter of the tube enabled the heat removal rate to be conserved in the facility. The tubes have the same material and thickness as the prototype, in order to preserve the heat flux and the wall temperature. Major design parameters of the PCHX are summarized in Table 3. In a manner similar to the PASCAL test, the wall temperature was measured at five points on the inner wall and outer wall along the tube length, to estimate the wall heat flux and the heat transfer coefficient. Also, a fluid temperature profile inside the PCHX was measured by installation of the thermocouples in a vertical direction in a similar way to the

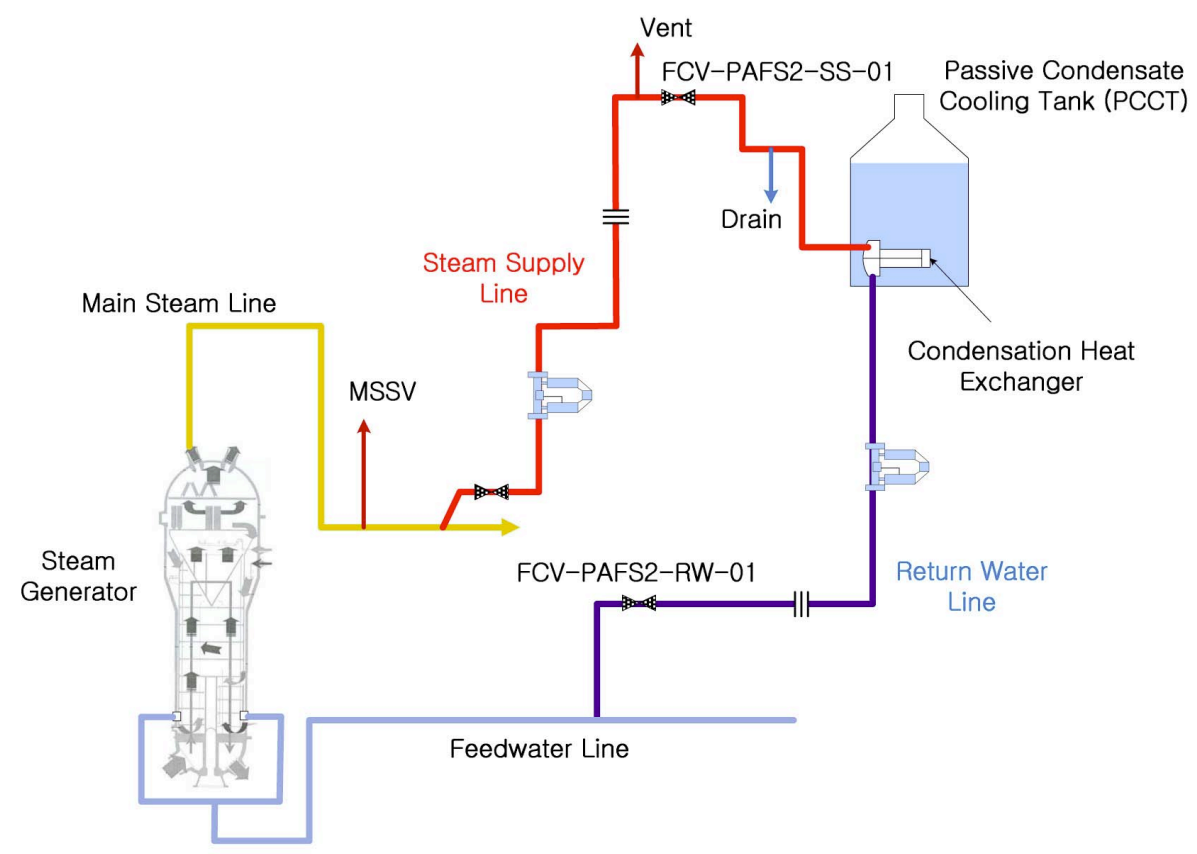

Fig. 17. Loop Configuration of the ATLAS-PAFS Facility 

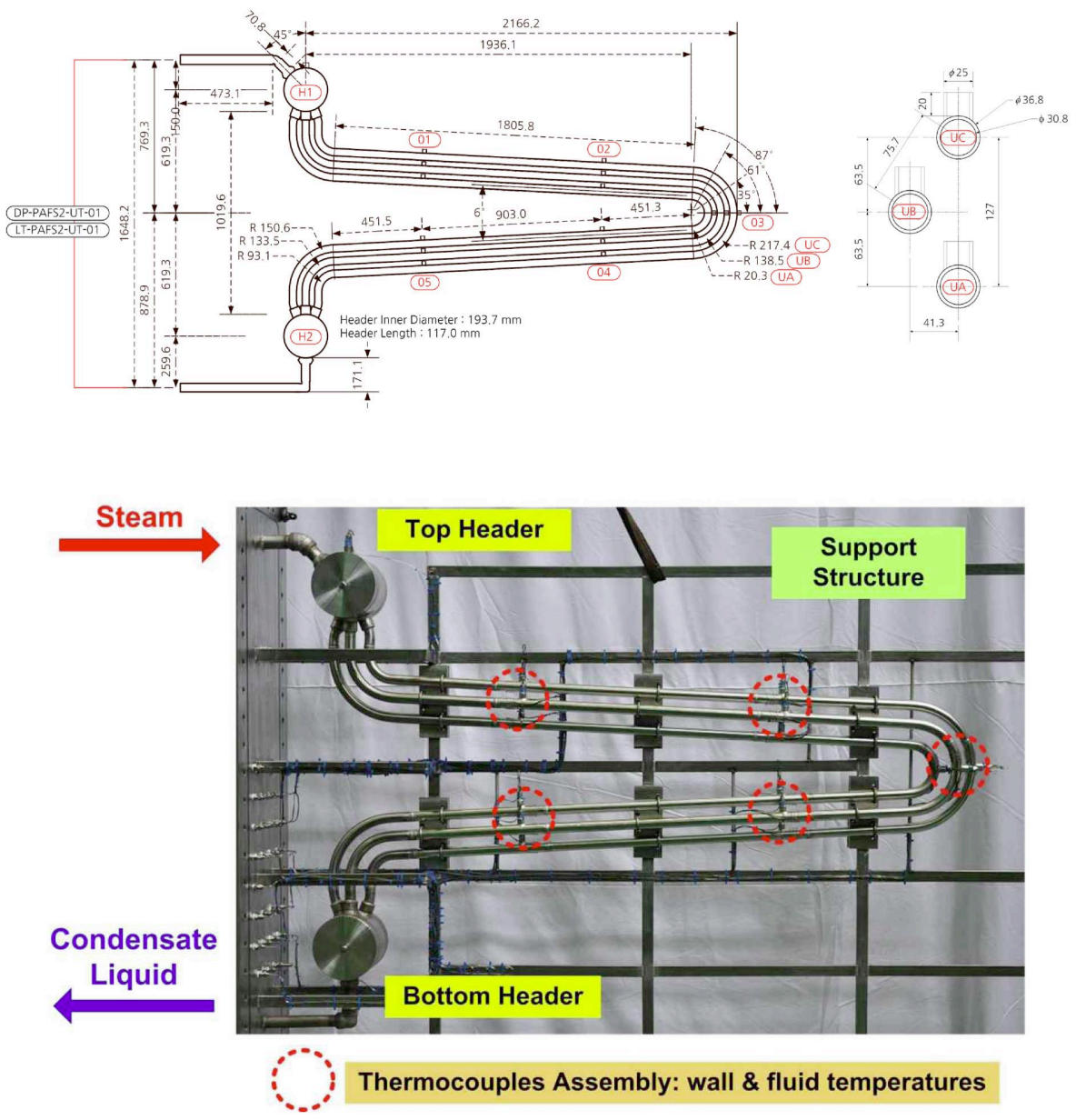

Fig. 18. Schematic Diagram and Photograph of the PCHX in the ATLAS-PAFS Facility

Table 3. Design and Scaling Distortion of the PCHX in the ATLAS-PAFS Facility

\begin{tabular}{c|c|c|c}
\hline Parameter & Ideal Design & Actual Design & Distortion (Actual-Ideal)/Ideal \\
\hline OD/ID(mm) & $35.92 / 31.678$ & $36.8 / 30.8$ & $+2.4 /-2.8 \%$ \\
\hline Number/PCC Tank & 2.91 & 3 & $+3.1 \%$ \\
\hline Avg. Length of each Tube (m) & 4.225 & 4.77 & $+12.9 \%$ \\
\hline Power/1Train (MW) & 0.592 & 0.649 & $+13.1 \%$ \\
\hline
\end{tabular}

PASCAL test. The PCCT was designed as a rectangular pool as shown in Fig. 19, which has a half-height scale and a reduced area, according to the global scaling ratio of ATLAS. The geometry of the PCCT is summarized in Table 4.

As shown in Table 3 and Table 4, there are some scaling distortions in the present ATLAS-PAFS facility compared to the ideal design. In this study, the effect of the scaling distortion in the facility was evaluated with a MARS code [10] for the PAFS-FLB-EC-01 test case. Despite some differences in the thermal hydraulic behaviors resulting from the scaling distortions, it could be confirmed from the MARS evaluation that the ATLAS-PAFS facility has the capability of reasonably simulating the transients during the PAFS actuation from an operational validation point of view. 


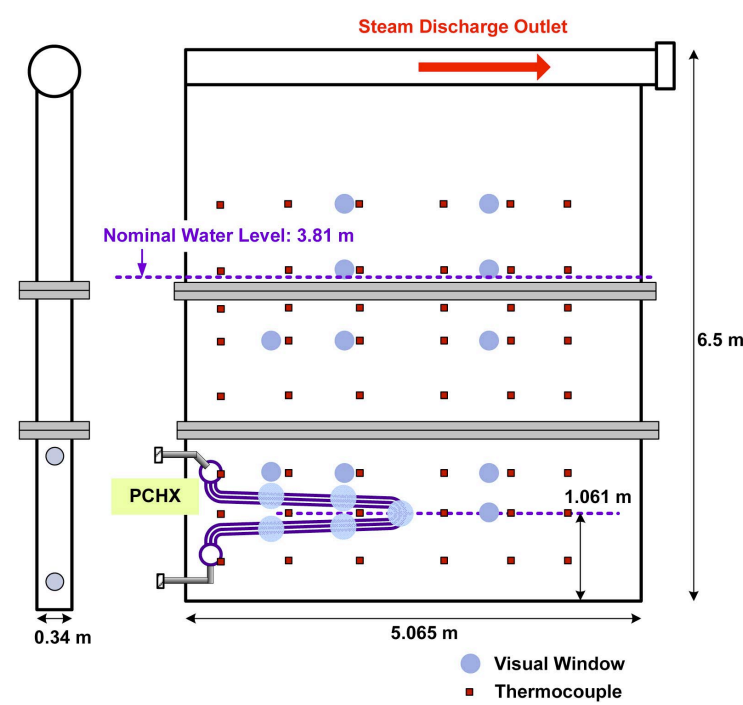

Fig. 19. Schematic Diagram of the PCCT in the ATLASPAFS Facility

Table 4. Design and Scaling Distortion of the PCCT in the ATLAS-PAFS Facility

\begin{tabular}{c|c|c|c}
\hline Parameter & Ideal Design & $\begin{array}{c}\text { Actual } \\
\text { Design }\end{array}$ & $\begin{array}{c}\text { Distortion } \\
\text { (Actual-Ideal)/Ideal }\end{array}$ \\
\hline Width $(\mathrm{m})$ & 0.34 & 0.34 & $0 \%$ \\
\hline Length $(\mathrm{m})$ & 4.44 & 5.065 & $+14.2 \%$ \\
\hline Area $\left(\mathrm{m}^{2}\right)$ & 1.504 & 1.722 & $+14.2 \%$ \\
\hline Height $(\mathrm{m})$ & 3.81 & 3.81 & $0 \%$ \\
\hline
\end{tabular}

\subsection{Experimental Result of the Integral Effect Test}

The initial steady-state conditions and the sequence of event in the FLB scenario for the APR+ were successfully simulated with the ATLAS-PAFS facility. When the reactor was tripped, both the reactor coolant pump (RCP) and the turbine were stopped concurrently The main steam isolation valve (MSIV) of each steam generator was closed right on an actuation of a low steam generator pressure (LSGP) trip signal. The water level of the affected steam generator (SG-1) decreased rapidly to empty due to the break flow. Contrary to the SG-1, the water level of the intact steam generator (SG-2) decreased continuously and reached the set-point of the passive auxiliary feedwater actuation signal (PAFAS), $25 \%$ of the wide range (WR) water level. The PAFAS opened the PAFS actuation valve (FCV-PAFS2RW-01 in Fig. 17) on the return-water line, and the heat removal by the natural convection of PAFS was initiated on the SG-2. As the primary system pressure decreased to the actuation set-point of the safety injection pump (SIP), the SIP water was supplied through two direct vessel injection (DVI) nozzles, i.e. DVI-1 and DVI-3. Table 5 shows the sequence of events observed in the present PAFS-FLB-EC-01 test.

Following the reactor trip induced by the LSGP signal, the coolant inventory of the secondary system of the intact steam generator was reduced by the repeated opening and closing of the MSSV as shown in Fig. 20. The pressure and the temperature of the primary system continuously decreased during the heat removal by the PAFS operation as shown in Fig. 21. The water in the PCCT was heated

Table 5. Sequence of Events in the PAFS-FLB-EC-01 Test

\begin{tabular}{l|c|c|l}
\hline \multicolumn{1}{c|}{ Event } & DAS Time $(\mathrm{sec})$ & Time after Break (sec) & \multicolumn{1}{c}{ Remarks (Set-point) } \\
\hline Break opening & 403 & 0 & Concurrently with the break \\
\hline Main feedwater stop \& MFIS & 403 & 225 & PT-SGSD1-01 $=5.895 \mathrm{MPa}$ \\
\hline LSGP & 628 & 225 & Concurrently with the LSGP \\
\hline Reactor trip (Decay power start) & 628 & 225 & Concurrently with the reactor trip \\
\hline RCP trip & 628 & 225 & 0.14 s after the reactor trip \\
\hline Turbine trip & 628 & 237 & 12.02 s after reactor trip \\
\hline $8 \%$ power & 640 & 258 & PT-SGSD2-01 = 8.1 MPa \\
\hline First open of MSSV SG2 & 661 & 791 & LT-SGSDRS2-01 level $=2.78 \mathrm{~m}$ \\
\hline MSIV SG2 Close & 1194 & 791 & LT-SGSDRS2-01 level $=2.78 \mathrm{~m}$ \\
\hline PAFS SG-2 Actuation & 1194 & 3185 & PT-PZR-01 = 10.72 MPa \\
\hline LPP signal & 3788 & 3206 & LPP + 21.64 s delay \\
\hline SIP injection & 3809 & Not actuated & PT-PZR-01 < 4.03 MPa \\
\hline SIT injection & - & &
\end{tabular}


up to the saturation condition by the heat transfer from the PCHX tube surface. In the PAFS-FLB-EC-01 test, the major sequence of events was ended before the water level decrease in the PCCT. Fig. 22 shows a natural circulation flow measured at the return-water line during the PAFS actuation. When the PAFS actuation valve was open, the water in the return-water line and the PCHX drained to the SG-2 through the economizer nozzle, so that the mass flow rate measured by a flow meter at the return-water line showed a peak value of $0.775 \mathrm{~kg} / \mathrm{s}$ at 1205 seconds, as shown in Fig. 22, and the collapsed water level of the SG-2 increased to $3.1 \mathrm{~m}$, as presented in Fig. 20. After the drainage of the coolant in the returnwater line and the PCHX, the natural convection flow in the PAFS loop was stably formed without any instability until the end of the transient as shown in Fig. 22. From the present experimental result, it could be concluded

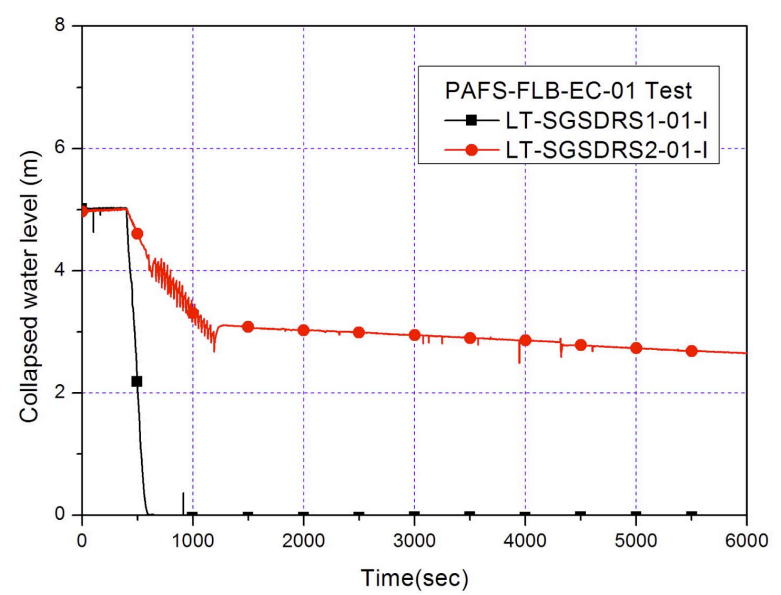

Fig. 20. Collapsed Water Levels in the SG Secondary Side in the PAFS-FLB-EC-01 Test

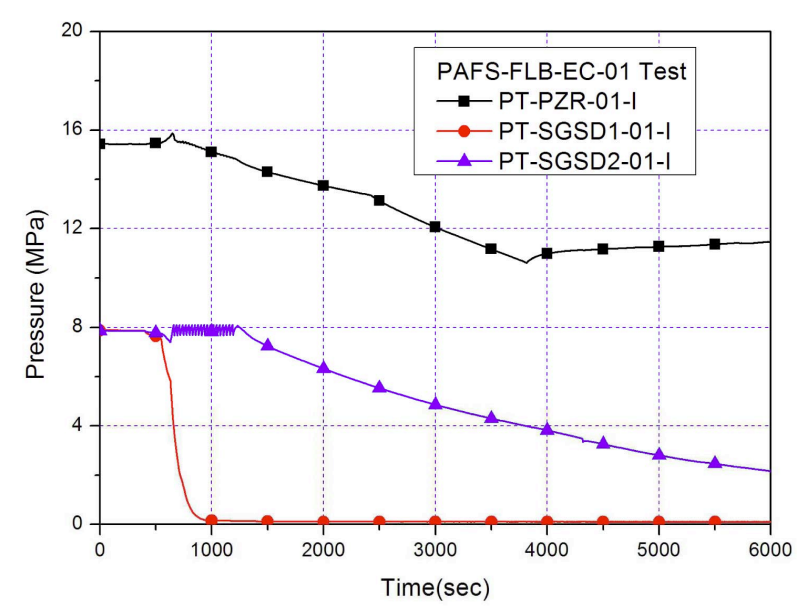

Fig. 21. Variation of Primary and Secondary Pressures in the PAFS-FLB-EC-01 Test that the APR+ has the capability of coping with the hypothetical FLB scenario by adopting PAFS and the proper set-points of its operation.

\section{UNCERTAINTY ANALYSIS}

An uncertainty of the measured experimental data was analyzed in accordance with a $95 \%$ confidence level. According to the ASME performance test codes 19.1, the uncertainty interval of the present results was given by the root-mean-square of a bias contribution and a precision contribution [11]. The bias and precision errors were evaluated from the data acquisition hardware specifications and the calibration results performed once every year, respectively. Table 6 shows analyzed uncertainty levels of each group of instruments.

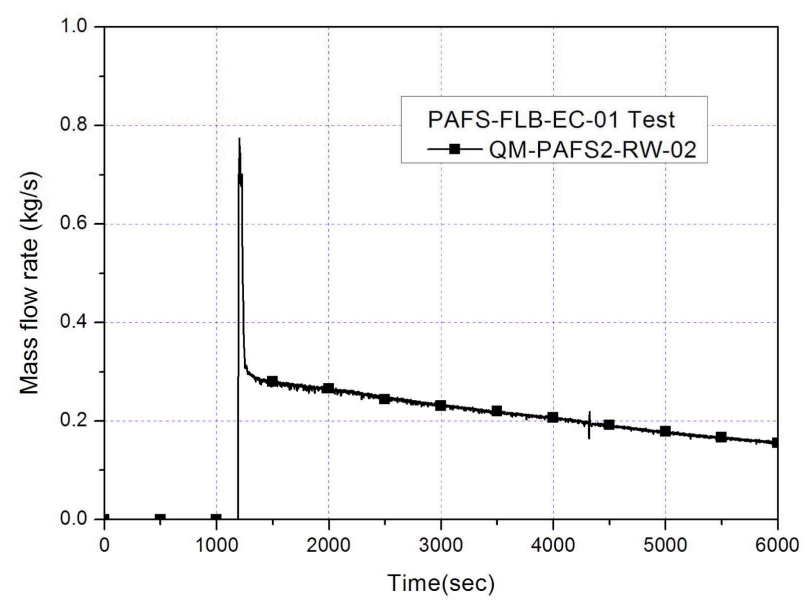

Fig. 22. Natural Circulation Flow of the PAFS in the PAFSFLB-EC-01 Test

Table 6. Uncertainty Levels of Instruments

\begin{tabular}{l|c|c}
\hline \multicolumn{1}{c|}{ Parameter } & Unit & Uncertainty \\
\hline Static Pressure & $\mathrm{MPa}$ & $0.56 \%$ \\
\hline Differential Pressure & $\mathrm{kPa}$ & $6.7 \%$ \\
\hline Collapsed Water Level & $\mathrm{m}$ & $4.0 \%$ \\
\hline Temperature & ${ }^{\circ} \mathrm{C}$ & maximum $4.4^{\circ} \mathrm{C}$ \\
\hline Flow rate & $\mathrm{kg} / \mathrm{s}$ & $2.65 \%$ \\
\hline Heater Power & $\mathrm{W}$ & $\pm 0.595 \%$ \\
\hline Heat Flux (Tube, Pool side) & $\mathrm{W} / \mathrm{m}^{2}$ & $\pm 15.3 \%$ \\
\hline Heat Transfer Coefficient (Tube side) & $\mathrm{W} / \mathrm{m}^{2} \mathrm{~K}$ & $\pm 3.1 \%$ \\
\hline Heat Transfer Coefficient (Pool side) & $\mathrm{W} / \mathrm{m}^{2} \mathrm{~K}$ & $\pm 2.6 \%$ \\
\hline
\end{tabular}




\section{CONCLUSION}

Experimental programs have been launched with an aim of validating the cooling and operational performance of the APR+ PAFS. For an effective and comprehensive evaluation, the validation experiment is composed of two kinds of test: i.e. a separate effect test and an integral effect test. In the separate effect test, PASCAL, the heat removal rate of a single PCHX tube was quantified, and the natural convection phenomena in the loop were examined. The present separate effect test result proved that the current design of the PCHX satisfied the heat removal requirement of the APR+ PAFS for cooling down the reactor core during the anticipated accident transients. As the first integral effect test for PAFS, the PAFS-FLB-EC-01 test was performed to simulate a FLB on the pipe connected to the steam generator economizer with an equivalent break size of $0.3 \mathrm{ft} 2$, which was analyzed as the most severe case in the APR+ SSAR. The initial steady-state conditions and the sequence of event in the FLB scenario for the APR+ were successfully simulated with the ATLAS-PAFS facility. As PAFS actuated, the natural convection flow in the PAFS loop was formed without any instability, and the collapsed water level in the intact steam generator was maintained steadily. The pressure and the temperature of the primary system continuously decreased during the heat removal by the PAFS operation. From the present experimental result, it could be concluded that the APR+ has the capability of coping with the hypothetical FLB scenario by adopting PAFS and the proper set-points of its operation.

The local thermal-hydraulic parameters measured in the PASCAL experiment will contribute to improve the model of the condensation and boiling heat transfer, and also to provide the benchmark data for validating the calculation performance of a thermal hydraulic system analysis code or a computational fluid dynamics (CFD) code with respect to PAFS. The integral effect test data will be used to evaluate the prediction capability of existing safety analysis codes of MARS, RELAP5, as well as the SPACE code, and to identify any code deficiency for an FLB simulation with an operation of PAFS.

\section{ACKNOWLEDGMENTS}

This research has been performed as a part of the nuclear R\&D program supported by the Ministry of Knowledge Economy of the Korean government.

\section{REFERENCES}

[1] C. H. Song, T. S. Kwon, B. J. Yun, K. Y. Choi, H. Y. Kim, H. G. Jun, "Thermal-Hydraulic R\&Ds for the APR+ Developments in Korea," ICONE18, Xi' an, China (2010).

[2] J. H. Choi, J. Cleveland, N. Aksan, "Improvement in Understanding of Natural Circulation Phenomena in Water Cooled Nuclear Power Plants," Nuclear Engineering \& Design, 241, 4504-4514 (2011).

[3 ] J. Cheon et al., "The Development of a Passive Auxiliary Feedwater System in APR+ Track 1: Water-Cooled Reactor Programs \& Issues," ICAPP2010, San Diego, USA (2010).

[4] W. P. Baek, C. H. Song, B. J. Yun, T. S. Kwon, S. K. Moon, S. J. Lee, "KAERI Integral Effect Test Program and the ATLAS Design," Nuclear Technology, 152, 183195 (2005).

[ 5 ] A.N. Nahavandi et al., "Scaling laws for modeling nuclear reactor systems," Nucl. Sci. \& Eng., 72, 75-83 (1979).

[6] C. H. Song, B. D. Chung, K. H. Kang, H. O. Kang, B. J. Yun, Y. S. Bang, H. J. Seong, S. J. Hong, S. K. Sim, "Development of the Phenomena Identification Ranking Table (PIRT) for the Passive Auxiliary Feedwater System (PAFS) of the APR+," Transactions of the Korean Nuclear Society Spring Meeting, Jeju, Korea (2012).

[7] M. Ishii, I. Kataoka, "Similarity Analysis and Scaling Criteria for LWRs Under Single Phase and Two-Phase Natural Circulation," NUREG/CR-3267, ANL-83-32 (2004).

[ 8 ] K.H. Kang, S.K. Moon, H.S. Park, S. Cho, K.Y. Choi, B.J. Yun, T.S. Kwon, S.J. Yi, C.K. Park, B.D. Kim, Y.S. Kim, C. H. Song, W.P.Baek, "Detailed Description Report of ATLAS facility and Instrumentation," KAERI/TR-4316/ 2011, Korea Atomic Energy Research Institute (2011).

[ 9 ] Korea Hydro and Nuclear Power Co. Ltd., "APR+ Standard Safety Analysis Report (SSAR)”, 9-002-K-415-012 (2011).

[10] B.D. Chung et al., "MARS Code Manual Volume V: Models and Correlations," KAERI/TR-3872/2009, Korea Atomic Energy Research Institute (2009).

[11] The American Society of Mechanical Engineers, “Test Uncertainty," ASME PTC 19.1-1998 (1998). 